\title{
Hõimlane verejõe tagant: Saami muinaslood tootempõhjapõdrast. VII
}

\author{
$\underline{\text { Enn Ernits }}$
}

\subsubsection{Päikesejumalus}

\section{Kahekümne üheksas jutt}

"Mjandash põõrre." V. Tsharnoluski, 1927? ja 1936? < (?) Pjotr Sarvanov (snd 1877 paiku 1943). Monntsh; (?) Jefim Danilov (snd 1859 paiku) < Ilja ja Semjon. Turja, Lõmbes. Avaldatud Tsharnoluski 1962: 82-83; 1965: 74; 1971: 89; Koshetshkin 1983: 110.

V. Tsharnoluski kirjapaneku näitena avaldasin sarja esimeses osas (vt "Mäetagused", 1997, nي $\underline{4}$, lk 42) Meandashi-loo, milles tootemloomast oli saanud päikesepõder. Teen sellest sisukokkuvõtte, mis annab vastuse kahele küsimusele:

Kes on Meandash põõrre? Ta on päike. Tema tee on päikese teekond. Ta on lumivalge, kuldsete sarvedega. Meandash on Koola ja elu algus. Ta on karjamaade algus.

Mida teeb Meandash põõrre? Ta lendab maakera seest; ta lendab maa ühest äärest (Imandra kandist) teise. Ta lippab ühest maakohast teise. Igal pool talle ei meeldi. Ohverdamispaigas viljastas ta kusemisega maad. Ta pillas oma kuldse sarve maha ja lausus: See on tshiigr - Meandashi tundur!

Mainitud tüübist pole kahjuks rohkem teisendeid. Seepärast on võimatu kõnelda midagi selle sisuehtsusest. E. Autio (1993: 14) leidis, et raamatus "Saami muinasjutte" väidab V. Tsharnoluski loo olevat kuulnud Monntsha lahe äärselt P. Sarvanovilt, ent "Legendis inimpõdrast" nimetab ta loo esitajana Lõmbesi elanikku J. Danilovit. Ehk aitab siinpuhul päikese teekonna alguse meenutamine: Kintushi tagant, Imandra tagant ..., sest päike tõuseb ju idast. Mõlemad kohad paiknevad ju laias laastus samal geograafilisel laiusel, Imandra Koola lääneosas, Kintush sellest kaugel idas. Seega ei saa nimetatud lugu täies ulatuses pärineda turjalaselt J. Danilovilt (sama selgub Tsharnoluski 1965: 76 põhjal), küll aga Imandrast lääne pool olevast Monntshast, mis seondub P. Sarvanoviga, kellele nii Imandra kui ka Monntsh jäävad ida poole. See tuletus on õige muidugi juhul, kui muinasloo algus polnud juba varem kivinenud vormelina Turjasse kandunud. Loos on teises kohas mainitud, et päikesepõder ilmub Norra tagant, seega läänest. Siin on taas midagi ebaselget. Ehk on jutustaja maininud ka päikese maa-alust tagasiteed: kuidas siis muidu saaks ta igal hommikul idast taevasse tõusta. Nagu teada, oli V. Tsharnoluskil Koolas raskusi saami keele valdamisega - nii võis jääda midagi üles kirjutamata. Teisalt lubab müüdis mitme Ida-Koola toponüümi (Siivn, Keiva, Kintush) nimetamine, üks neist isegi detailne (Alajärv), oletada, et üheks jutustajaks võis olla siiski sealse kandi elanik.

Asjaomases muinasloos on kasutatud vastakaid väljendeid Kintushi tagant, Imandra tagant ja Limandrõ (= Imandra) tagant, kauge Norra tagant. Peale selle leiame teise variandi ka äikesejumaluse ohvri loost (26. jutt): Norra tagant, kauge Limandrõ tagant, kus on teispoolse elu algus (Tsharnoluski 1965: 80). Ka see pärineb väidetavalt turjalase suust ning klapib müüdiloogikaga, sest toonela paikneb maailma paljude rahvaste kujutelmades läänes, seal, kus loojub päike (Tailor 1989: 285 jj).

Nii näikse päikesepõdramüüt pärinevat mitmest allikast. See pole üllatav, sest ka äikesepõdralugu, nagu publitseerija isegi tunnistab, on kombineering (vt 26. lugu). Lisaks pole selge keelejuhi P. Sarvanovi päritolu.

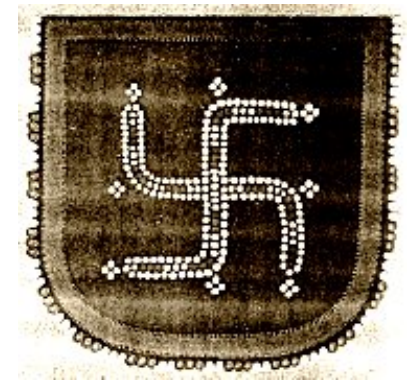


V. Tsharnoluski meenutuse järgi ei osanud J. Danilov laulu ise esitada, kuid oli sellest lummatud ja korrigeeris pidevalt kogujat (pole öeldud, kas keeleliselt või ka sisuliselt), liiati kui kõik muu rahva usuelust oli talle vastukarva:

Ainukese laplasena mõistis Jefim Danilov hukka Jovkõi vanakeste katsed taaselustada endiste jumalate kummardamine. Ta teadis rohkesti oma rahva usuelust, kuid minu küsimuste peale vastas ta siira põlglikkusega: "tühiasi", "jama", "mis sellest rääkida", "pole kõneväärt".

Ent Meandashi mü̈̈dist oli Jefim tõsiselt vaimustatud. Selle laulu tunnistas ta ehtlapilikuks - see oli tema meelest ilus, see "oli tõepoolest nõnda sündinud". Suutmata ise seda peast lugeda, nautis ta laulu Meandash põorrest minu esituses lõpmata kordi, ise norivalt vigu parandades. (Tsharnoluski 1965: 76).

V. Tsharnoluski kirjeldab rahvapärase ainestiku koguja meelest huvipakkuvalt, millist vaeva nägi 77-aastane J. Danilov muinasloo reprodutseerimise katsel:

Sulgenud silmad, pomises ta nähtavasti suurivaevu mälu pingutades midagi oma sinakate vanainimese-huulte vahelt. Kõrv tabas hädavaevalt kummalisi sõnu: oshtõr, põshtõr... janizam...

Näis, et ta meenutas mingit laulu.

"Äh vanadus, vanadus... mõistus jahmerdab. Aga mis küll kõik pähe ei tüki? Ilja ja Semjon, kadunukesed, laulsid seda. Mõistus jahmerdab, mõistus jahmerdab..."

Äkki hakkas ta rabelema, jäi poolpimedate silmadega valget paberilehte jöllitama ning seda nimetissõrmega tonkides, käskis:

"Kirjuta, pane nü̈̈d kirja! Kirjuta lapi keeles: õshtõr, põshtõr, kostoram, kolmogorra, niellegorra. Riitalahta janizam, imdid koz oakkad? *29 Pane nü̈̈d kibedasti kirja... See sinna alla, kuid algusesse kirjuta:

Kintushi tagant, Limandrõ tagant, kaugelt, kuskilt maa seest, merelt ookeanilt jookseb Meandash põorre, põhjapõdrakarja tshiigri algus... Meandash põõrre jookseb, Meandash põorre lendab... Ja äkki!..."

Jefim üritas tabada ja hoida peas kinni sagivate mõtete niiti, kuid see katkes. Higi valgus otsmikule, pisarad tulid silma.

"Pole parata, puterdan. Aga sina pane kirja, näe, kirjuta! Küll sa kodus nuputad, küll sa ise taipad, mis on oige."

Tuli midagi katkendlikku, käristatut, arusaamatut, mille mõtet ei suutnud ma algul tabada.

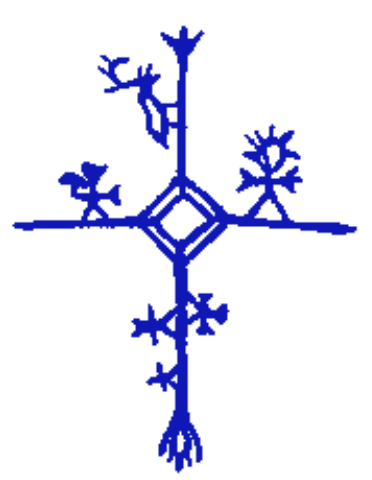

"Tatte tshigr, Meandash tshigr... See on tundur - Meandashi tundur!" $\stackrel{* 30}{ }$

Ta jäi jälle vait ja nõjatus padjale. Vanamees oli täitsa kuhtunud (Tsharnoluski 1965: 73; 1972: 22-23).

Käsitletav müüt, kui see on ehtne, näitab otse klassikalisel kom-bel, kuidas hõimu jumalusest, selle esivanemast ja põhjapõtrade haldjast on sündinud päikesejumalus. Arktilisel alal peeti päikest ülimalt tähtsaks. Mujal iseloomustab selle jumalustamine esmajoones maaviljelejate usundeid. Teada on koltade müüt, milles päike oma teekonnal ratsutab hommikul karu, keskpäeval sarva ja õhtul 
põhjapõdralehma seljas (Itkonen 1946: 8). Meandash-põõrre polnud ainuüksi päikese, vaid lühidalt öeldes kogu universumi sümbol, jutus mainitud elu ja maanurga algus (Autio 1993: $65)$.

Kuldsarvedega hirv ilmse päikesesümbolina esines muiste laialdasel maa-alal Doonauäärsetest steppidest Mongoolia kõrbe-teni. Seda kujutelma kajastavad imeilusad sküüdi ja tagaari kul-tuuri lendhirvi jäljendavad pronkskujukesed; tähelepanuväärsed on ka Mongoolia hirvekivi-del kujutatud arvukad lendavateks peetavad olendid ja solaarsümbolid. Hilisemal ajal on hirvlane (põder/põhjapõder/hirv) asendunud hobusega (Okladnikov, Martõnov 1972: 222-229; Kilunovskaja 1987: 104). Euraasia kaljutaides esineb sageli päikesepäiseid sõralisi (Novgorodova 1989: 171).

Maapealse kuldpõhjapõdra-kujutelm esineb Kildini saami Galina Sharshina andmeil rikkuse sümbolina. Teatud päeval võib see põder joosta inimesele vastu, helisev kelluke kaelas. Kui teda silitada, siis hakkab tema küljest kulda pudenema. Seejuures ei saa unustada, et ei tohi minna liiale, muidu muutub kuld rauaks (Szabò 1967: 44-45). Kuldsarvedega põhjapõder osutus ühes tuntud saami muinasjutus päästjaks kohutava söögiisuga savimehe eest (Szabò 1967: 90-91). Ilmselt selle heateo eest määrisid pääsenud mehed, neiud hoidsid looma kinni, tal sarved kullaga kokku ja otsustasid,

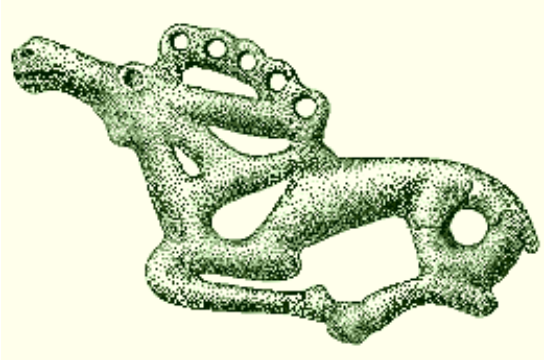
et tegu on kuldsarvedega põhjapõdraga. Koguja on paigutanud selle loo "Muinasjutud inimestest ja loomadest" rubriiki, kuid paremini oleks see sobinud peatükki "Uuemad muinasjutud, laenatud motiivid".

Meandashil on lisanimi põorre, mis tähendab head. Sõna on suguluses eesti ja soome sõnaga paras. Meandash ongi saamide heategija. Ta paneb põhjapõdrakarjamaad haljendama. Kus leidub vabalt elavaid põhjapõtru, seal on ka elu! Ent siingi närib uurijat kahtluseussike!

T. I. Itkoneni sõnaraamatu järgi tähendab käsitletav sõnaühend kujul Meantazh-byyrre hoopis (põhjapõdra)saaki (Itkonen 1958: 245)! Siit järgneb oletus, ehk on V. Tsharnoluski ühendist valesti aru saanud. Seda näikse kinnitavat ka alljärgnev katkend:

Jermi tõukas põhjapõtra toorelt jalaga ning pööras ta teisele küljele.

"Mientush põorre! Jestratile toidupooliseks", lausus ta põlglikult (Tsharnoluski 1965: 67).

Ka teine Meandash-põõrre nimega seonduv juhtum, mis on küll iseenesest kaunis ja salapärane, ei heida asjaloo selgitamiseks piisavalt valgust. V. Tsharnoluski mainis, et saamid kujutlesid, et metsikud põhjapõdrad võivad lennata, kusjuures valgeid laike külgedel nimetati tiibadeks (Tsharnoluski 1962: 300). Ka äikesejumaluse eest põgenev põhjapõder lendab nähtamatute tiibade varal (Tsharnoluski 1965: 80). Järgneva katkendiga üritas autor tõestada, et kaljult kaljule hüppav põder jätabki mulje lendavast jumalusest:

"Lasmitrai, vaata!"hü̈̈an vanameest tasakesi varrukast sikutades.

Imeilus, haraliste sarvedega põhjapõdrapull seisis päris kaljutipul ja näis millegi üle mõtisklevat. Tema poosis oli seletamatult võimukat, ta valis teed, kuhupoole söösta.

See kestis vaid mõne hetke. Sarvas võpatas korra, heitis pea uhkelt kuklasse, lendas pü̈̈dliku hüppega teise, peaaegu meie pea kohal kõrguva kalju tippu ning kadus seejärel silmist.

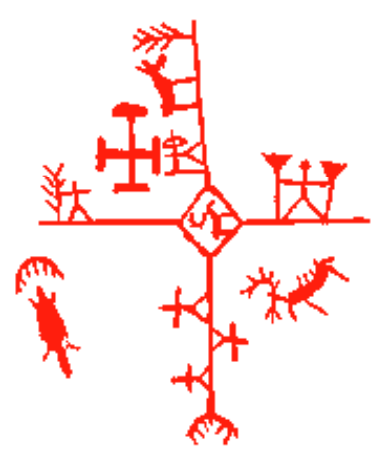


"Ai ai! Vaata, mis ta seal teeb! Mis ta küll ometi teeb! See ta on!" Vana laplane vaatas mulle vaimustatult otsa.

"Ai ai ai!" väärutas ta pead. "Meandash põorre ise on välja tulnud!"

"Mis see tähendab, Meandash põorre?" küsisin mina.

"Aga sa ju ise nägid teda. Tema see oligi."

"Kuid ma nägin lihtsalt metsikut põhjapõtra."

Lasmitrai muigas endale habemesse, heitis, nagu mulle tundus, hellitleva pilgu, kuid ei lausunud ei musta ega valget. (Tsharnoluski 1965: 52).

Kes võib väita, et siinpuhul pidasid saamid silmas müütilist põhjapõtra? Võib-olla - see on tõenäolisem - vaimustuti saagi pärast, sest teisal on ju väidetud meandasheid ei näe keegi ning keegi ei tea, kust neid leida (Tsharnoluski 1972: 117). Tuleb välja, et peame pigem uskuma T. I. Itkoneni sõnaraamatu teadet.

Kuldsete sarvedega päikesepõtra kujutati lumivalgena. Nagu kirjanduses väidetud, hindasid saamid valgeid põtru kõrgelt. Nende seostamine päikesega on mõistetav. Nii saamid kui ka teised põhjarahvad (neenetsid ja tunguusid) ohverdasid talle valgeid põtru (Itkonen 1960: 127, 129, 130, 131). Päikesele ohverdati isasloom, sest ka päike ise pidavat olema meessoost (Andelin 1858: 257).

Käsitletavast muinasloost ilmneb, et Meandash valis paikkonna, kus talle ohverdati. Müüdis Oajmkedzhpoallaks nimetatud kõrgendikul leidus kaks pühaks peetavat loodusrelikti (Tsharnoluski 1972: 41). Ohvrikohas Meandash urineeris. Nimetatud kujutelm võis tekkida nii, et taolises paigas muutus rohi uriinilämmastiku tagajärjel lopsakamaks. Rohukasvu ja päikese vaheline seos ilmneb ka teates inari saamidelt: suvel palunud nad päikest, et ta kasvataks rohtu; selleks valmistatud päikesekuju, mis ümbritsetud sarvedest taraga (tshoarve-kärdi) (Itkonen 1943/1944: 64). Meresaamide keskel olevast kolta kolooniast pärineb kelleltki Ondreilt järgmine lugu. Poeg läks laskma metspõhjapõtru Naistekaljule, kus oli suur kari, kuid tal onnestus tappa vaid üks loom. Siis meenus talle, et tegu on tema surnud isa ohvripaigaga, mille väljenduseks oli saare teise otsa tehtud sarvetara (Lagercrantz 1961: 204). Ühelt XVII sajandi jooniselt on näha, kuidas seida ümber on paigutatud sarved poolsõõrina, mis võikski olla käsitletav tara (vt «Mäetagused», 1998, $\underline{\text { nr 8) }}$.

Selles muinasloos leidub veel üks huvipakkuv motiiv:

Siis aga pillas maha oma sarve, kuldse sarve... ja lausus:

"See on tshiigr - Meandashi tundur! Nende küngaste tippudele Meandashi sarv, sarv peast..."

Viimane lause puudub V. Tsharnoluski vahepealses teoses (Tsharnoluski 1965). Sellest katkendist ilmneb mahapillatud sarve seos paikkonna karjamaaga, kus põhjapõdrad saavad rammusat rohtu ja kus neil meeldib peatuda, et kütid saaksid neid kätte. Ilmselt samadest seisukohtadest lähtus ka V. Tsharnoluski, kes tõlgendas selle sarve saami müütiliseks tshuorv tshulta'ks (ka tshuarrv tshuolt) - sarvevaiaks, mille külge saab kujutletavalt siduda põhjapõdrakarju (vt 3. ekskurss; Tsharnoluski 1972: 42).

Sarved väljendavad erinevate rahvaste uskumustes rikkust, viljakust, jumalikku väge jm positiivset (vt Cooper 1986: 82). Võimusümboliks on peetud kaht sarve saami haugihaldjal haauga-mad'du, vahel ka iherusehaldjal taabmoh-mad'du. Sarvelisi kalu kujutatakse samuti hantide usundis (Kuusi 1976: 315, 316; Itkonen 1938: 60; Itkonen 1945/1946: 134). Ka käesolevas muinasloos on peategelane talle meeldiva paikkonna valdaja; sellele viitab ta ütluski. Kujutletava sarvevaia külge olevat seotud ka kodupõtru (3. ekskurss). V. Tshar- 
noluski mainis, et Siberis leiduvad lasilatena tarvitatavad keeruliste sümbolitega monoliitsed sarvevaiad, millel domineerivad põdrakujutised (Tsharnoluski 1966: 309). Huvipakkuv on A. Martõnovi teade, et meie ajaarvamise eelse aastatuhande altai kunstis sümboliseerisid sarved looduse taassündi ja taimset jõudu ning samaaegselt ka zoomorfset elupuud (Martõnov 1985: 233).

\section{Kolmas ekskurss}

Saamide sarvevaia paremaks mõistmiseks aitab kaasa ka eespool nimetatud P. Sarvanovilt V. Tsharnoluski poolt 1935. aastal kirja pandud imepärane lugu:

Elas üks taat. Tal oli karjas palju (kodu)põhjapõtru. Ise oli ta aga teadmamees. Ta mõtles, et vaja põhjapõdrad järjele tõsta. Kuid tal ei jätkunud jõudu. Tal jäi puudu põhjapõtrade niesst'ist ( $\left.{ }^{\star} 31\right)$. Seepärast palus ta teist meest, samuti teadjat... Mõlemad uinusid, jäid magama... Peremees nägi unes, et teadja $\left.{ }^{*}{ }^{*} 2\right)$ moondus põhjapõdrapulliks ja jooksis lõuna suunas. Ta lippas ise kannule. Jooksid ja jooksid, kuni jõudsid soo servale. Oli siin alles kari! Tohutu suur kari!

Karja seast astus talle vastu juhtsarvas. Kaks pulli läksid kokku ja hakkasid võitlema. Äkki murdis võitja pull teisel loomal kaela. Ta paigutas karja enda poole ümber.

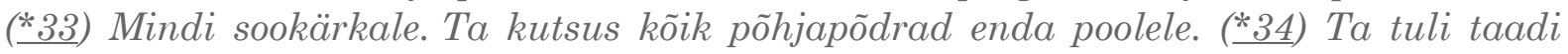
juurde ja küsis:

"Noh, kuhu ma panen nende põhjapõtrade niesst'i! Kuhu käsed sarvevaia maasse

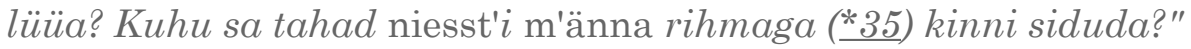

Peremees vastu:

"Jänesemäele."

Teadmamees ajaski karja Jänesemäele, lõi sarvevaia maa sisse ja sidus selle külge m'änna rihma.

Peremees ärkas üles ja mõtles:

"Ena, milline unenägu! Kui see täide läheb, siis leeb mul palju põhjapõtru!" Ta äratas eide üles ja lausus:

"Tõuse, eit, üles! Keeda vägev lõunasöök. Ma nägin und,

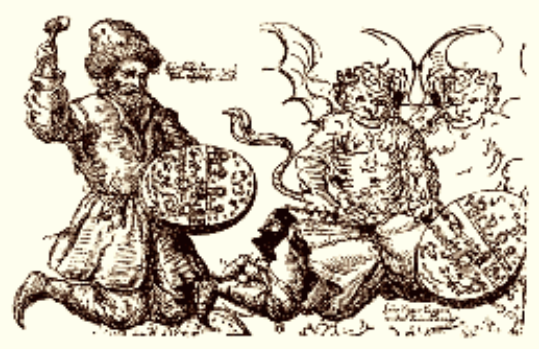
väga head und! Tuleb seesama vanamees, kelle juures ma käisin unenäos abi palumas, külla kutsuda!"

Naine tegi söögi valmis, mees tõi lapiku pudeli viina. Läks siis peremees külalist kutsuma. See tuli kohale ja hakati napsutama. Peremees küsis teadmamehelt:

"Mis sa unes nägid?"

Teadmamees vastu:

"Mis sa ilmaasjata pärid? Sa käisid ju minuga ühes ja nägid kõik, mis ma tegin; milleks sa enam pärid? Mida sa palusid, seda ka tegin. Sa käskisid lü̈̈a Jänesemäele sarvevaia ja selle külge kinnitada m'änna rihmaga niesst'i."

Noh, peremees lausus:

"Jah, nägin küll unes kõiki sinu ettevõtmisi, kõike, mida sa tegid."

Teadmamees lausus:

"Kari on aetud sinu juurde, niesst on jäljega kinni pandud, jälg on tapetud. Keegi ei saa enam karja ära viia." 
Kui külaline hakkas koju minema, sõnas peremees:

"Aitäh, sulle, paljuteadja!"

Ja ongi kogu lugu (Tsharnoluski 1966: 309-310).

Müüditeksti lähem analüüs ei mahu käesoleva sarja raamidesse. Märgitagu vaid, et saam võis vaimujõu tugevuse varal teha imet. Ta suutis ületada piiri võõra ja oma vahel ning teha võõra põdrakarja omaks. Nagu jutust selgub, pidi nõid selleks saama juhtsarvast võitu, siduma tema karja kujuteldava rihmaga kujuteldava vaia külge ning tapma jälje. See oli muistses usundis tähtsal kohal: jälge sai pöörata, seda sai vangistada ja seda sai tappa.

\section{Lõpetuseks}

Oleme Meandashi-lugudega ühele poole jõudnud. Kõik ei läinud konarusteta. Sarja sai kirjutatud osade kaupa, seepärast ei teadnud alati, kas kõik oletused ja tekstilõigud klapivad järgnevaga. Liiati kummitas pidev ajapuudus. Autor loodab käesoleva uurimuse järgnevates väljaannetes, näiteks CDvariandis, kõik ebakohad siluda.

Esialgu ei kujutanud siinkirjutaja isegi ette, et Emakeele Seltsi rahvaluule sektsiooni koosolekul peetud tunnisest ettekandest kasvab välja raamatu mõõtu andev seitsmeosaline sari. Kas nüüd

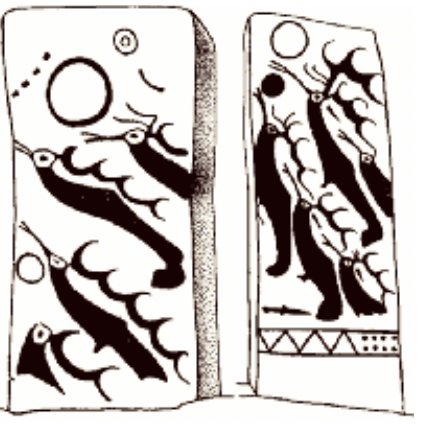
on teema ammendunud? Kindlasti mitte. Venemaa arhiivides võib leiduda avaldamata tekste, samuti pole õnnestunud tutvuda paari kitsama levikuga trükisega. Autorile pole teada, kas ja kus on säilinud V. Tsharnoluski Koolas tehtud märkmed ja nende hilisemad ümberkirjutused. Koolaski tuleks veel koguda mis koguda annab.
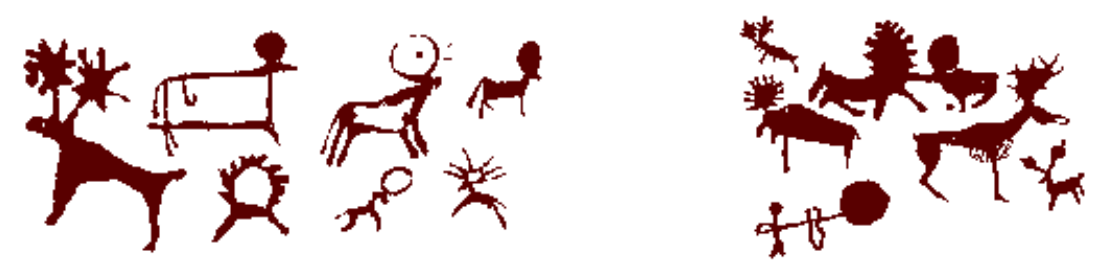

\section{Illustratsioonid}

Joonis 39. Saami ornament. Haruzin 1890 järgi. Haakrist väljendas paljude rahvaste muinasusundis päikest (Cooper 1986: 188).

Joonis 40. XVIII sajandi algusest pärineva shamaanitrummi keskosa, kus rombiga on tähistatud päikest. Rydving 1991: 40 järgi. Tähelepanu väärib kumerate sarvedega põhjapõder, mis võis olla vikerkaare võrdkujuks.

Joonis 41. XVII sajandi algusest pärineva shamaanitrummi keskosa. Kjellström 1991: 112 järgi. Kõrvutamine eelmise illustratsiooniga lubab pidada põdrakujutist päikeseks. Põder vibuküti ees võib väljendada äikesejumaluse ohvrit (vt Mäetagused, nr 9). Trummikujutiste identifitseerimine ja interpreteerimine pole veel lõppenud. 
Joonis 42. Laplane lööb nõiatrummi. Samuel Rheeni joonistus (1671). Haavio 1947: 85 järgi. Trummil on näha taevakehakujutisi. Paremal on kurat mehe oma võimusse haaranud.

Joonis 43. Tagaari kultuuri päikesehirv Kuzbassist. I aastatuhandest eKr. Okladnikov, Martõnov 1972: 223 järgi.

Joonis 44. Hirvekivid oletatavate lendhirvede ja päikese kujutistega. Okladnikov, Martõnov 1972: 226 järgi.

Joonis 45. Päikest sarvedel kandvaid loomi Sise-Aasia kaljutaides Novgorodova 1989: 171 järgi.

\section{Parandusi trükitud väljaandele}

Sarja eelmistes osades on autori süül tekkinud numbrilisi ebatäpsusi. Nii tuleb pealkirjas 4.2.1.2 («Mäetagused», 1997, $\mathrm{nr} 5, \mathrm{lk} 43$ ) asendada jaotisega 4.1.2.1.2; pealkiri 4.1.2.3. («Mäetagused», 1998, nr 6, lk 33) asendada numbritega 4.1.2.1.3. ning 4.1.2.4. numbritega 4.1.2.2.

Ebatäpsusi esineb ka avaldatud muinaslugude leheküljenumbrites (õiged numbrid on trükitud rasvaselt): II jutt («Mäetagused», nr 4, lk 47) - Kert 1980: 221 (nr 138); IV jutt (sealsamas, lk 50) - Kert 1980: 221-222 (nr 139); V jutt (sealsamas, lk 51) - Itkonen 1931-1936: 70-72; X jutt (Mäetagused, nr 5, lk 51) - Kert 1980: 218-219 (nr 136).

Ajakirja «Mäetagused» nr 7 leheküljel 34 on kaheksanda jutu käsitlemisel ekslikult kirjutatud «...see põhiliselt kaheksanda jutuga kattuv (vt eestpoolt) ning seitsmeteistkümnenda loo iseärasused...» See tuleb lugeda järgmiselt: «kaheksas jutt kattub põhiliselt seitsmeteistkümnenda looga, mille iseärasused...» Ka samas lõigus esitatud jutuvestja kommentaar pole võetud neljandast loost, nagu nimetatud, vaid seitsmeteistkümnendast.

\section{Kirjandus}

(lisaks eelmistes numbrites loetletule)

Andelin, A. 1858. Kertomus Utsjoen pitäjästä Suomi lk 173-299.

Cooper, J. C. 1986. Lexikon alter Symbole. Leipzig.

Itkonen, T. I. 1938. Tunturilappalaisten kansantietoa Inarista. Kalevalaseuran vuosikirja 18, lk 54-62.

Kilunovskaja, M. Je. 1987. Interpretatsija obraza olenja v skifo-sibirskoi iskusstve (po materialam petroglifov i olennõhh kamnei. Skifo-sibirski mir: Iskusstvo i ideologija.

Novosibirsk, lk 103-107.

Kuusi, M. 1976. Kaloista vanhin. Kalevalaseuran vuosikirja 56, lk 306-327.

Lagercrantz, E. 1961. Lappische Volksdichtung 5: See- und Skoltelappische Texte des

Südlappischen Varangergebiets. Suomalais-ugrilaisen Seuran toimituksia, 124. Helsinki.

Martõnov, A. I. 1985. Ideja solntsa i vozrozhdenija zhizni u drevnihh narodov Severnoi Azii:

(Po arheologitsheskim dannõm). Rerihhovskije tshtenija 1984 goda: Materialõ konferentsii.

Novosibirsk, lk 233-237.

Novgorodova, E. A. 1989. Drevnjaja Mongolija: (Nekotorõje problemõ hronologii $i$

etnokulturnoi istorii). Moskva. 
Szabò, L. 1967. Kolalappische Volksdichtung (Texte aus den Dialekten in Kildin und Ter). (Abhandlungen der Akademie der Wissenschaften in Göttingen, Philologisch-historische Klasse. Dritte Folge, N 68). Göttingen.

Tailor (= Tylor), E. B. 1989. Pervobõtnaja kultura. Moskva.

Tjarnoluskij, V. V. 1993. Den vilda renen i myt och rit. Jokkmokk.

\section{Kommentaarid}

29 Saamikeelses katkendis Õshtõr, põshtõr... on arusaadavad vaid üksikud sõnad, vrd kooz 'kuhu', kollm 'kolm', niell'e 'neli', nel'l'i-kierdash 'neljakordne', oakkad 'joosta (looma kohta)'.

30 Turjasaami tshigr - põhjapõtrade karjamaa. V. Tsharnoluski on vist siinpuhul seganud ära selle turja sõnaga tshaarra 'tunduriseljandik'.

31 Saami niesst - põhjapõtrade vastastikune külgetõmbejõud karjas (V. Tsharnoluski märkus). Ehk on seoses sõnadega nõssted ja neestam 'mängus vastast võitma'?

32 Kutsutud teadmamees võitis lõunapoolse sarva ja võttis tema karja üle, allutades selle endale (V. Tsharnoluski täiendus).

33 Kutsutud teadmamehe ümber (V. Tsharnoluski täiendus).

34 Peremehele, kel oli vähevõitu põhjapõtru (V. Tsharnoluski täiendus).

35 m'änna rihm - Ohi põhjapõtrade sümboolseks kinnisidumiseks noore põhjapõdra nahast, mispuhul sarved olid kaetud pehme, sametise nahaga (V. Tsharnoluski märkus; temal männo higna). 